Article

\title{
Interdisciplinary Design of Vital Infrastructure to Reduce Flood Risk in Tokyo's Edogawa Ward
}

\author{
Supriya Krishnan ${ }^{1, *,+}$, Jiabiao Lin ${ }^{1,+}$, Johannes Simanjuntak ${ }^{2, \dagger}{ }^{+}$, Fransje Hooimeijer ${ }^{1, \dagger}$, \\ Jeremy Bricker ${ }^{2,+}$, Maayan Daniel ${ }^{3,+}$ and Yuka Yoshida ${ }^{1,+}$ iD \\ 1 Department of Urbanism, Faculty of Architecture and the Built Environment, Delft University of Technology, \\ 52628 Mekelweg, The Netherlands \\ 2 Department of Hydraulic Engineering, Faculty of Civil Engineering and Geosciences, \\ Delft University of Technology, 52628 Mekelweg, The Netherlands \\ 3 Department of Architecture, Faculty of Architecture and the Built Environment, \\ Delft University of Technology, 52628 Mekelweg, The Netherlands \\ * Correspondence: supriya.kr09@gmail.com \\ + These authors contributed equally to this work.
}

Received: 2 December 2018; Accepted: 16 July 2019; Published: 13 August 2019

check for updates

\begin{abstract}
Engineering for flood resilience of dense coastal regions often neglects the resultant impact on urban design quality. Vital subsurface infrastructure such as hydraulic systems, water networks, civil construction, transport, energy supply and soil systems are especially important in shaping the urban environment and integrating resilience. However, the complexity and resource intensive nature of these engineering domains make it a challenge to incorporate them into design measures. In the process of planning, this impedes proactive collaboration between the design and engineering communities. This study presents a collaborative design engineering exercise undertaken to find spatial solutions to flood-prone Edogawa ward in Tokyo, Japan. The team included urbanists, hydraulic engineers, water resource managers, and landscape architects. Hydraulic engineering solutions were combined with spatial planning methods to deliver two alternative strategies for the chosen site. Each alternative was then evaluated for its urban design quality and effectiveness in reducing flood risk. The exercise highlighted that successful design requires comprehensive interdisciplinary collaboration to arrive at a sustainable bargain between hard and soft measures.
\end{abstract}

Keywords: hard vs. soft countermeasures; flood risk; storm surge; critical infrastructure; resilient cities

\section{Introduction}

Cities across the globe are threatened by increasing flooding from coastal, fluvial and pluvial sources which must be considered in engineering and spatial design. This is compounded by urban densification that increases the exposure of population at risk. Building flood resilience in the built environment involves reducing the risk and damages from disasters. This 'risk' is defined as the product of 'probability' of an event occurring with the 'consequence' of that event [1] whereas 'resilience' is defined as "the ability of a system to adjust in the face of changing conditions (events)" [2]. The scientific consensus on resilience is that it needs multidisciplinary cooperation and an integrated approach which in flood risk consideration is about engineering and spatial design [3]. In the current spatial development landscape, reduction of 'probability' has assumed priority by investments in protective infrastructure such as dams, dikes, gates and levees that shield the built environment from the impacts of the hazard. Rising intensities and frequencies of hazards due to climate change can overwhelm such defense structures, suggesting a need to shift focus from reducing 'probability' towards reducing the 'consequences' of the hazard. 
This consequently implies that spatial development becomes part of the risk approach and engineering becomes part of spatial design. The integrated approach needs more than multidisciplinary cooperation. It requires not only respecting each other's expertise, but also critical discussions, questioning and understandable argumentation defined as interdisciplinarity [4]. Currently there is a knowledge gap on how the new relation between spatial development and flood risk engineering can be performed in an interdisciplinary fashion [5].

This paper reflects on interdisciplinary research performed by urbanists, hydraulic engineers, water resource managers, and landscape architects aimed at flood resilience in dense built environments. Due to the shift from probability to the consequences of a hazard, the research scope is narrowed; instead of looking at the whole urban system (functions, social, economic) the focus is kept to the consequences of flooding on vital subsurface systems (transport conduits, water systems, gas lines, soil etc). Vital subsurface infrastructure, such as conduits for hydraulic systems, water networks (sources, supply, drainage), civil construction, transport conduits (roads and railways), energy supply and soil systems are long lasting and require massive initial investment. However, in general education and practice, design and engineering are operationally independent and have evolved their own lines of thought. This makes it hard to commit to long-term decision-making. This paper assesses the role of vital subsurface infrastructure in shaping flood resilience strategies in current practice and explores a test case to evaluate the integration of engineering and design.

Understanding the future renewal of urban flood defense systems through their dependence on the subsurface infrastructure that fundamentally determines their form, is essential for long-term thinking. Hence, the research question primary to this investigation is "how can interdisciplinary research in planning urban flood defense systems in relation to vital (sub)surface infrastructure improve the potential for long-term resilience?"

\section{Context}

Tokyo is the most populous metropolitan region in the world. It has been historically subjected to floods, typhoons and earthquakes; the frequency and intensities of which have been rising. As a multi-hazard urban environment, Tokyo has long formulated flood control measures, emergency evacuation systems and a river management system [6].

Tokyo has traditionally used hydraulic structures (levees, gates, etc) for flood risk management. It is now exploring mega projects such as 'super levees' to better integrate risk management measures in the urban environment. A conventional levee is around three to four times as wide as it is high. The super levee is a high standard river embankment which is about 30 times as wide (around $300 \mathrm{~m}$ ) as it is high; such that even if it is over-topped, the flowing water does not breach the levee and instead flows slowly across its top surface $[7,8]$. As opposed to conventional flood barriers which essentially cut a city off from the water, the super levee provides an opportunity for better transitions between land and water while offering a superior level of flood protection. As one of the most ambitious attempts by any government to integrate flood defense infrastructure with urban development, the concept sees its share of opposition in the technical and social spheres. Criticism includes exceptionally high costs, long construction time frames, displacement issues and the claim that it is a product of "a systemic addiction to construction where government subsidies rather than real infrastructure need drives development" [8,9].

The objective of this research is to propose two planning alternatives to the conventional approach to the super levee which are evaluated both for their hydraulic effectiveness and urban design quality. The engineering and design layout of the alternatives are assessed to see how they impact the existing subsurface infrastructure networks, what must be modified to improve the effectiveness of the intervention and ultimately to reduce the consequences of the hazard.

\section{Methods}

As an 'exploratory' and 'interdisciplinary' research, a combination of quantitative and qualitative analysis techniques were adopted by utilizing the expertise of three urbanists, one architect, three 
hydraulic engineers, one water resources manager and three landscape architects. The first condition for this type of research is performing the research in a multidisciplinary team. Multidisciplinary and interdisciplinary are, according to [10], part of a sequence of typologies for enterprises within and across disciplines. In this sequence 'intradisciplinary' is within one discipline; 'cross-disciplinarity' is a viewing of one discipline from the perspective of another which involves several disciplines that each provide a different perspective on a problem; and 'multidisciplinary' is the integration of the contributions of several disciplines to a problem and is about assembling interdependent parts of knowledge into harmonious relationships (see Figure 1).

The term 'interdisciplinary' is is best understood not as one thing but as a variety of different ways of bridging and confronting the prevailing disciplinary approaches or, "as states the generic all-encompassing concept and includes all activities which juxtapose, apply, combine, synthesize, integrate or transcend parts of two or more disciplines" [11]. A higher level of integrated research and practice is 'transdisciplinary', concerned with the unity of intellectual frameworks beyond the disciplinary perspectives [12].

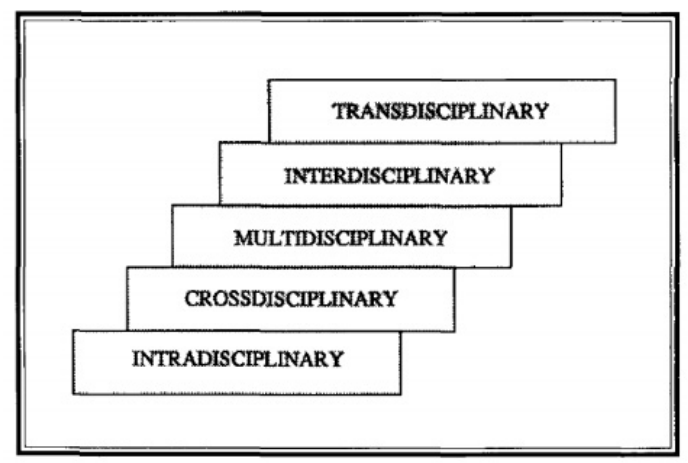

Figure 1. Stember's Disciplinary Typology for enterprises within and across disciplines [12].

Methods concerning interdisciplinary working attempt to reach an integrated approach via collaboration on integrating interest and needs [13]. In this research there are five steps taken that can be defined as the 'Dutch approach' [14]. This term refers to the multidisciplinary approach which Dutch urban designers and landscape architects adopt in pursuit of solutions to complex problems. Their role is to visualize and create connections between creativity and knowledge on the one hand with an analysis of the relevant societal issues and stakeholder interests on the other. Designers organize this via a process called "research by design $(\mathrm{RbD})$ ". $\mathrm{RbD}$ is any kind of inquiry in which design is a substantial part of the research process in which various scenarios are examined, alternatives considered and choices made [15]. Designers reveal a future situation and the consequences of this creation. It forms a pathway through which new insights, knowledge, practices or products come into being and makes room for multiple design iterations before detailed frameworks may be laid down (see Figure 2). However, this method has a drawback of sometimes not being detailed enough for engineering design calculations or being too detailed for urban design [15,16].

This is an interesting method of collaboration as "design" in the fields of engineering and urbanism do not denote the same activity. While in urban design, one finds common ground, to find the right measures for problems and goals, especially when all are unknown or open [17]; for engineers, the term design mainly refers to optimization processes to find the best solution. Here the difference between 'tame' problems that are clearly defined and solvable (engineering) and 'wicked' problems that are unclear in a fuzzy context (urban design) is crucial [18]. Using the "design" outcome itself to inform research lies at the crux of $\mathrm{RbD}$. 


\begin{tabular}{|c|c|c|}
\hline \multirow{2}{*}{ Measures $\downarrow$} & \multicolumn{2}{|c|}{ Problems and goals $\rightarrow$} \\
\hline & $\begin{array}{l}\text { Familiar and with } \\
\text { existing agreement }\end{array}$ & $\begin{array}{c}\text { Unfamiliar and there is } \\
\text { no agreement }\end{array}$ \\
\hline Known & Optimization & Negotiation \\
\hline Unknown & Innovation & Design \\
\hline
\end{tabular}

Figure 2. Definition of strategies characterized by the existing interpretation on the problem and goal definition and the agreement on measures [17].

This research aimed deliver a methodological approach to integrate knowledge on creating flood risk resilience. It filled the knowledge gap on how the new relation between spatial development and flood risk engineering can be performed in an integrate fashion. This paper is structured along the following five steps (see Figure 3):

1. Creating an inventory of existing projects for flood risk management measures (based on literature review, refer to Supplementary Materials).

2. Analyzing the chosen site that is under consideration for construction of the super levee (see Figure 4).

3. Proposing planning alternatives for the test site.

4. Evaluating the alternatives and their relationship with selected multidisciplinary perspectives (hydraulic engineering, urban design quality and vital subsurface infrastructure).

5. Process and analysis using $\mathrm{RbD}$.

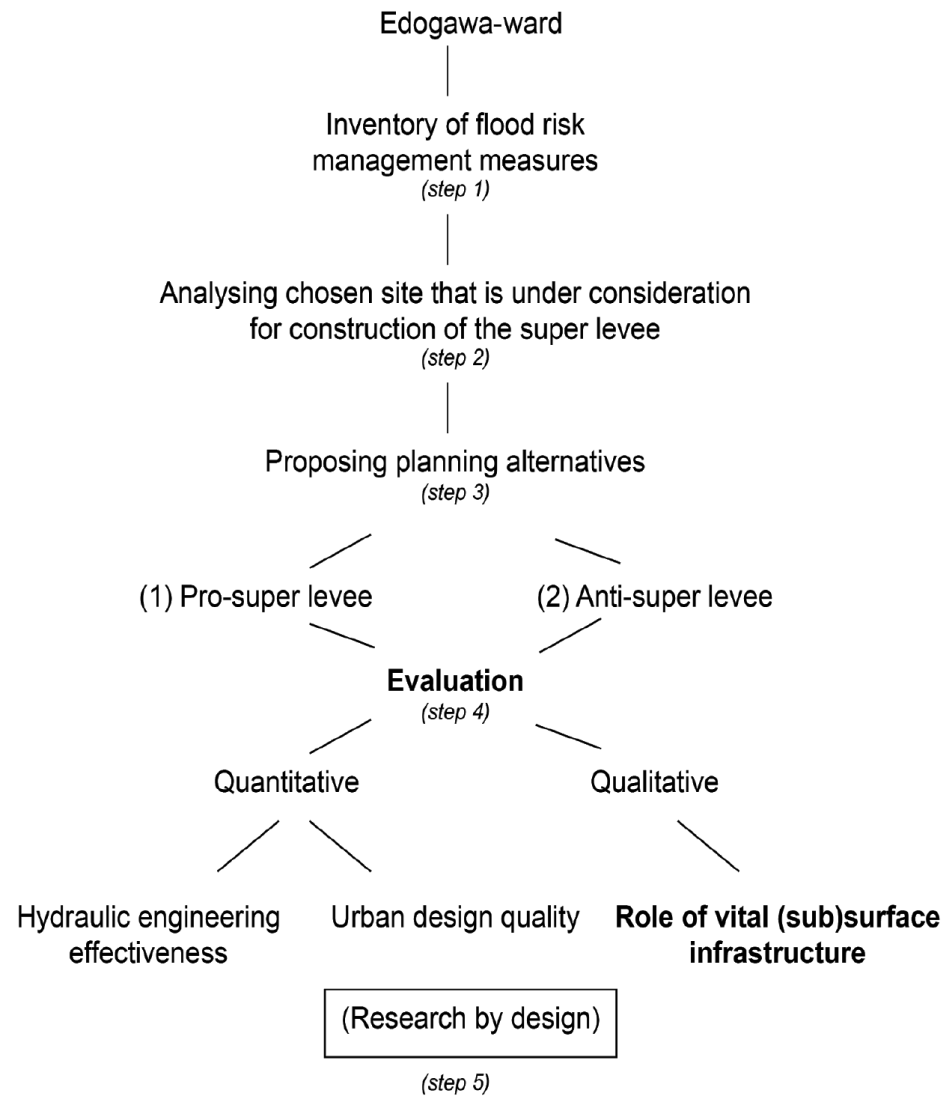

Figure 3. Research method and process diagram. 


\subsection{Step 1: Creating an Inventory of Existing Projects for Flood Risk Management Measures (Based on Literature Review)}

To understand flood defense interventions across different scales, an inventory of existing projects in the city was generated for three spatial hierarchies/scales (see Table 1). The macro (city) scale was utilized to grasp an overview of the flood defense philosophy (protective vs. adaptive). The meso (district or ward) scale was adopted for a nuanced analysis of the components that build the built environment. The micro (urban block) scale is an indication of how the flood defense system is translated into the urban space that citizens experience. The selection of initiatives included projects by public authorities, private developers, academia and allied partnerships. The objective of the inventory was to contextualize the Edogawa ward case study within the larger scales of Tokyo's planning through the following steps:

- $\quad$ Studying the geographical/political boundaries that control water resources management decisions and the governing bodies involved at each scale to understand the scope of decision making.

- Understanding geographical context, water governance systems, water usage and water-related interventions based on 'capacities' and 'impact of scale'.

- Understanding the implications of these designs in spatial terms from city to urban block scale. This has been done through a mapping exercise.

Based on the inventory generated, the following observations were made [6]:

1. Tokyo allocates substantial resources to managing risk. It accepts greater residual risks and emphasizes how to deal with them (Preparedness-response-recovery approach).

2. Tokyo employs a composite system of protective flood defense infrastructure, river management and social response infrastructure to combat emergencies.

3. Tokyo uses a combination of standard levees (offering 1 in 100-year probability event protection) combined with large-scale underground retention reservoirs to 'divert and balance' the water level in the event of excess rains.

Table 1. Flood defense projects catalogued based on function and scale [4-9,19-22].

\begin{tabular}{|c|c|c|c|}
\hline & Protect & Store & Channel \\
\hline & $\begin{array}{l}\text { The Capacity to Protect } \\
\text { Against Water }\end{array}$ & $\begin{array}{l}\text { The Capacity to Store/ } \\
\text { Buffer Water }\end{array}$ & $\begin{array}{l}\text { The Capacity to } \\
\text { Channelize, } \\
\text { Discharge Water }\end{array}$ \\
\hline $\begin{array}{l}\text { Macro-City/Region } \\
\text { (Tokyo Bay) }\end{array}$ & $\begin{array}{l}\text { (1) Super levee (Komatsugawa) } \\
\text { (2) Earthquake resistant levees } \\
\text { (3) Shoreline protection } \\
\text { (floodgates, sluices, locks, } \\
\text { pump stations, tidal } \\
\text { defence walls) }\end{array}$ & $\begin{array}{l}\text { (1) Regulating reservoirs } \\
\text { (Kuromebashi/Metropolitan Area } \\
\text { Outer Underground Discharge } \\
\text { Channel, Kasukabe/Kanda } \\
\text { River/Ring Road No. } 7 \\
\text { Underground Regulating Reservoir) } \\
\text { (2) Engineered diversion channels } \\
\text { (3) Floodways }\end{array}$ & $\begin{array}{l}\text { (1) River channel } \\
\text { improvement }\end{array}$ \\
\hline $\begin{array}{l}\text { Meso-Ward/district } \\
\text { (Edogawa) }\end{array}$ & & (1) The Green Tokyo Decade Project & \\
\hline $\begin{array}{l}\text { Micro-Urban block } \\
\text { (urban parcels/block } \\
\text { in Edogawa) }\end{array}$ & $\begin{array}{l}\text { (1) Disaster prevention pier- } \\
\text { Etchujima, Sumida River }\end{array}$ & $\begin{array}{l}\text { (1) Greening of dike } \\
\text { slopes/riversides project } \\
\text { (2) Tsurumi multipurpose } \\
\text { detention basin }\end{array}$ & \\
\hline
\end{tabular}

\subsection{Step 2: Analyzing the Chosen Site That Is under Consideration for Construction of the Super Levee}

The meso (district or ward) scale was chosen as the scale for proposing planning alternatives and conducting analysis (see Figure 4). The Edogawa ward is situated on the north perimeter of Tokyo Bay. 
Located close to the open sea, it is protected by the recently reclaimed Kasai Rinkai Park at its southern boundary; this is an area of relatively high elevation. Two rivers lie on the west side of Edogawa ward. The Arakawa river is an engineered channel that diverts upstream discharge to the northern part of Tokyo to reduce the risk of fluvial flooding in important areas. Similarly, the Nakagawa is also an engineered water channel with the main purpose of maintaining the water balance in Edogawa's polder system (see Figure 5).

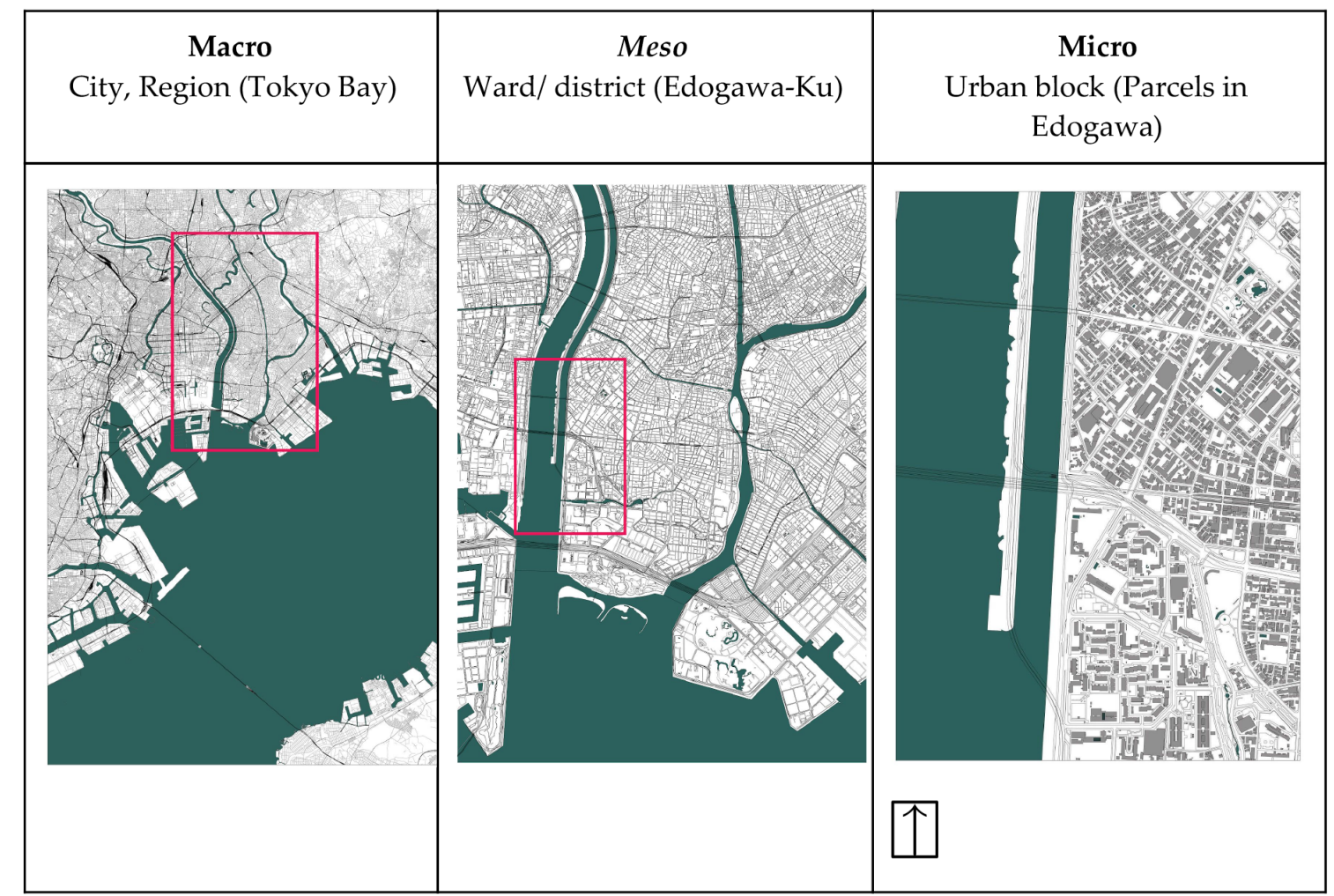

Figure 4. The city of Tokyo and the site in focus for analysis (Source: www.openstreetmap.org, maps not to scale).

Levees protect the west and east perimeters of Edogawa-ku. Within the city, several engineered channels serve as paths to extract water from urban areas using pumping stations (see Figure 6). The rising population density and the disappearing natural streams continue to exert pressure on the urban system and increase vulnerability to floods $[6,20]$. 


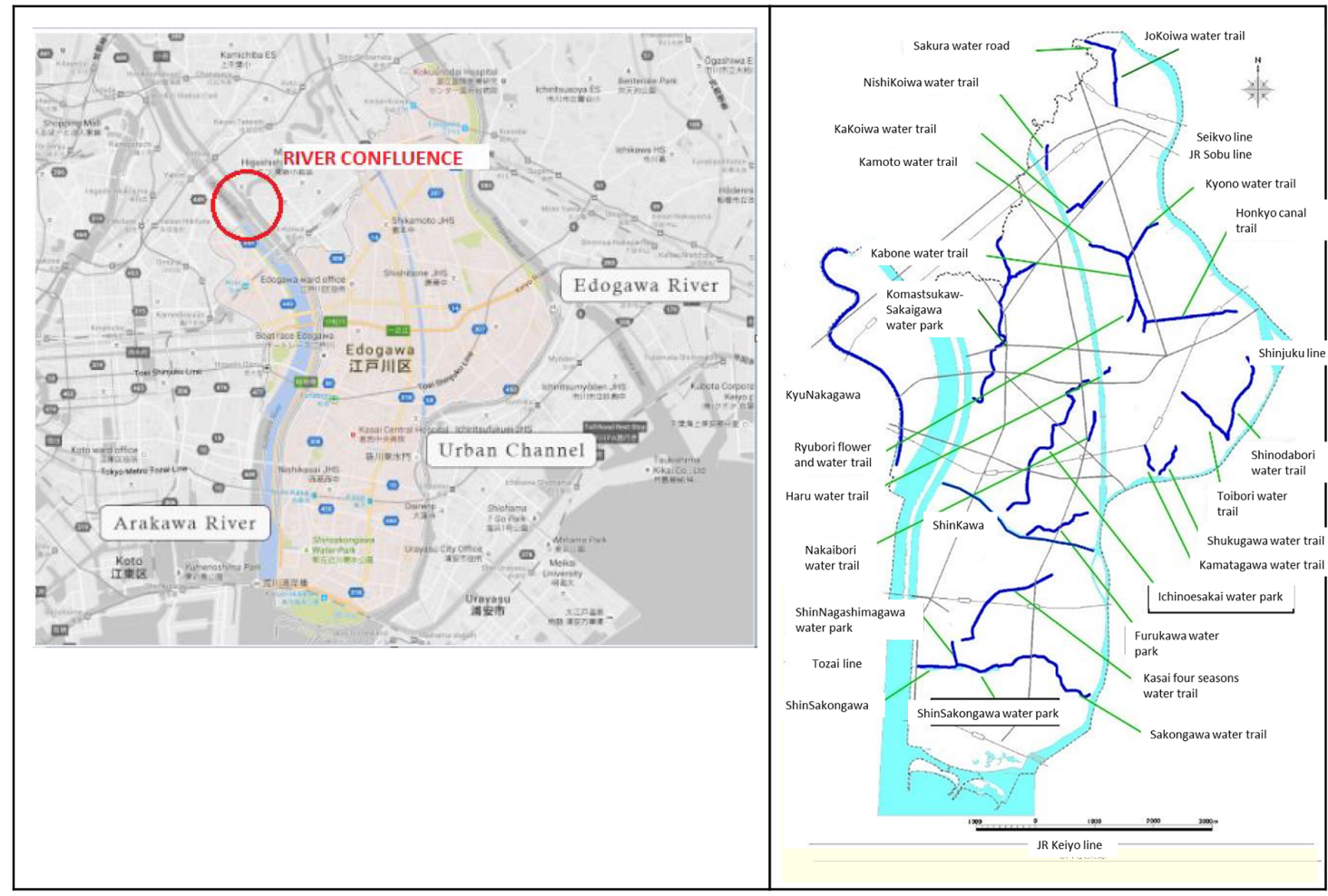

Figure 5. Map of Edogawa-ku with the rivers (left) and the waterways within its vicinity $[19,23]$ (Map source: Google Maps).

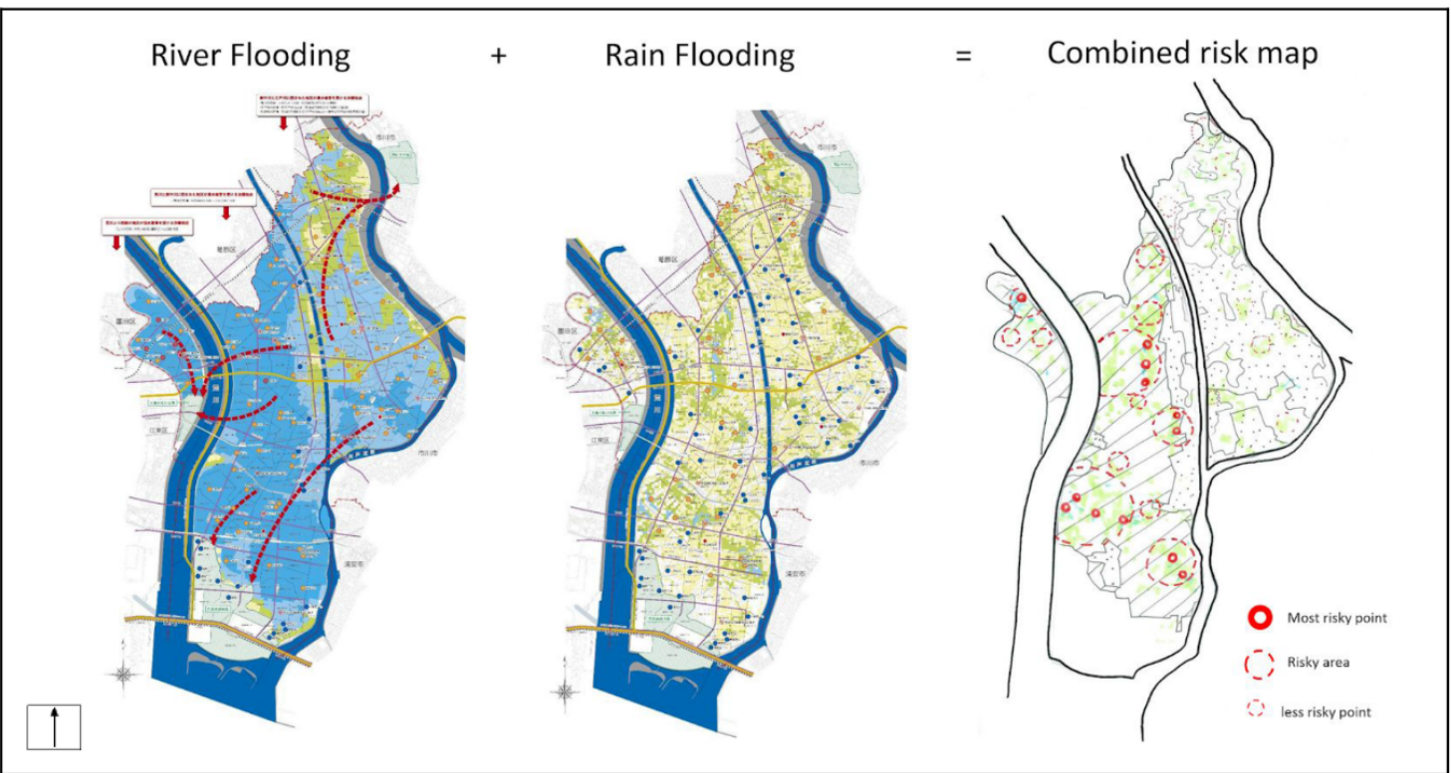

Figure 6. Risk zones (water ponding areas at the meso (ward) scale are identified using the: (left) drainage map of the two rivers flanking the Edogawa ward; (middle) drainage system of the Edogawa ward (data and map source: Ministry of Land, Infrastructure, Transport and Tourism (MLIT) Japan) $[19,20]$. Note that the left map indicates flooding from high river water levels, which can be caused by either high upstream (river) flows, or coastal storm surge (maps not to scale).

\subsection{Step 3: Proposing Planning Alternatives for the Test Site}

A two-week international workshop called 'Rethinking the super levee' was organized in Tokyo [24] (see Figure 7). Broad urban design and hydraulic engineering frameworks were proposed 
for the Edogawa-ku test site to assess how these may be adapted for the future. Given the complexity of multiple specializations and practical knowledge involved in the assessment of subsurface infrastructure, a common initial method called $\mathrm{RbD}$ was adopted.

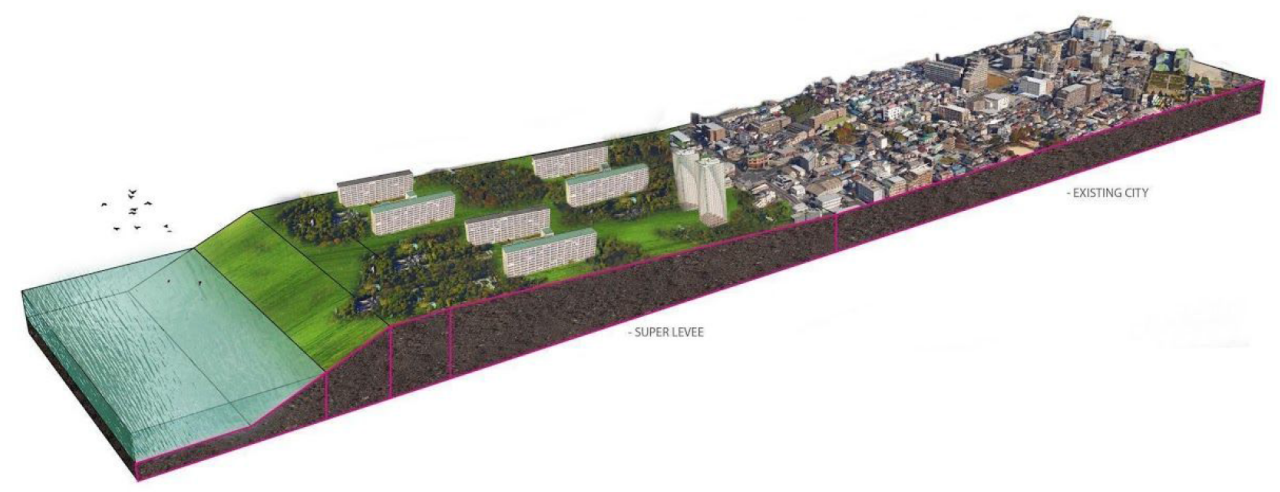

Figure 7. Visualization of the super levee for Edogawa-ku, Tokyo (source: base map from Google Earth and modelled by authors).

At the workshop, hydraulic engineers developed boundary conditions for urban flood risk management at the macro (city) scale. Threats to Edogawa-ku were qualitatively analyzed to propose upstream and downstream mitigation measures (such as water diversions and storm surge barriers). In addition, suggestions were made to improve existing engineered components on site including, (1) creating a streamlined interface between the levee and the water to minimize erosion; (2) installing sheet pile on the dike crown for additional freeboard as well as under the dike for seismic stability (prevention of settlement during liquefaction of the foundation); (3) establishing broad levee dimension; ; and (4) optimizing the urban drainage system. Based on the advantages and disadvantages of the proposed flood risk management framework, two teams with a mix of specialist disciplines collaborated to propose two planning alternatives:

- Strategy A: finding an alternative solution to the super levee that may provide the same level of protection for the chosen boundary condition;

- Strategy B: finding better ways of integrating the super levee into the urban area as opposed to the conventional blanket approach where a massive large levee runs along the entire urban coastline.

3.4. Step 4: Evaluating the Alternatives and Their Relationship with Selected Multidisciplinary Perspectives (Hydraulic Engineering, Urban Design Quality and Vital Subsurface Infrastructure)

The proposed site was evaluated primarily by using the Dutch layer approach [25]. The Dutch layer approach was introduced in the national debate on spatial planning in the Netherlands. It is a stratified model for site analysis that distinguishes planning components on the basis of the spatial dynamics of the substratum as follows: (1) natural blue-green systems such as green buffers and water; (2) Infrastructure (man-made structures for flood control, and conduits for transport, water, and fuel); and (3) Occupation patterns (human settlements). The approach was applied to Edogawa ward to understand the site thoroughly and spatially relate the existing flood control measures to the three layers mentioned above. The second method, system exploration environment and subsurface (SEES), was utilized to lay out the framework that looks more closely into interactions between constructed urban elements. This method was selected to systematically relate complicated engineering components and provide a framework with clear boundaries. for analysis. The resultant framework helped to generate broad recommendations to guide future resilience strategies for Edogawa-ku and to act as a template for similar cases. 


\section{Process and Analysis (Using Research by Design (RbD))}

The analysis and evaluation of proposed outcomes was done by using the method of "research by design". This method uses design to accelerate utilization of technical data into spatial conditions and lets the researchers understand and the unfamiliar complex context of Tokyo. The paper concludes with insights on how to unite multidisciplinary perspectives into design strategies for long-term resilience. The research scope was limited to data that were accessible in the public domain. This included practical urban design layers of buildings, open spaces, infrastructure, and vital subsurface infrastructure layers on soil, transport, power and water networks (see Table 2 and Figure 8). The following parameters were used for evaluation:

- Urban design quality to determine changes in population density, quality of the environment and economic impact.

- Evaluation of hydraulic engineering measures for calculating water balances based on the characteristics of the proposed interventions.

- Integration with vital subsurface infrastructure networks (sewer and storm drain pipe layout and capacity, electricity networks, waterways, transport (railways and roadways)). This was based on available knowledge of the layout, quality and capacity of infrastructure.

Table 2. Research scope following the Dutch layer method [25] and the system exploration environment and subsurface (SEES) method [26].

\begin{tabular}{|c|c|}
\hline Element & Status in This Study \\
\hline People & This was left outside the scope of this research \\
\hline Metabolism & This was left outside the scope of this research \\
\hline Buildings & $\begin{array}{ll}\text { - } & \text { Building footprint/ urban typology } \\
\text { - } & \text { Land use }\end{array}$ \\
\hline Public Space & $\begin{array}{ll}\text { - } & \text { Parks } \\
\text { - } & \text { Water bodies (lakes, rivers, creeks, lagoons, delta plains) } \\
\text { - } & \text { Artificial water channels (canals, streams, open drains) } \\
\text { - } & \text { Green cover typologies (marsh, swamp, agriculture) }\end{array}$ \\
\hline Infrastructure Layers & $\begin{array}{l}\text { Mapping man-made interventions for networks and utilities on the site } \\
\text { - Water (flood management interventions, storm surge barriers: dikes, pumps, } \\
\text { pipes, artificial levees, super dikes, overflow channels, spillway structures) } \\
\text { - Transport lines (roads, rails, others) }\end{array}$ \\
\hline Subsurface & $\begin{array}{l}\text { Mapping the natural characteristics of the site and the original topography } \\
\text { - } \quad \text { Geology/geomorphology: Soil type (delta plains, reclaimed land, alluvium) } \\
\text { - } \quad \text { Groundwater levels } \\
\text { - } \quad \text { Topography } \\
\text { - } \quad \text { Natural levees, water buffers } \\
\text { - } \quad \text { Underground pipelines (water, gas, waste water) } \\
\text { - } \quad \text { Underground structures (rainwater storage, tunnels, subways) }\end{array}$ \\
\hline
\end{tabular}




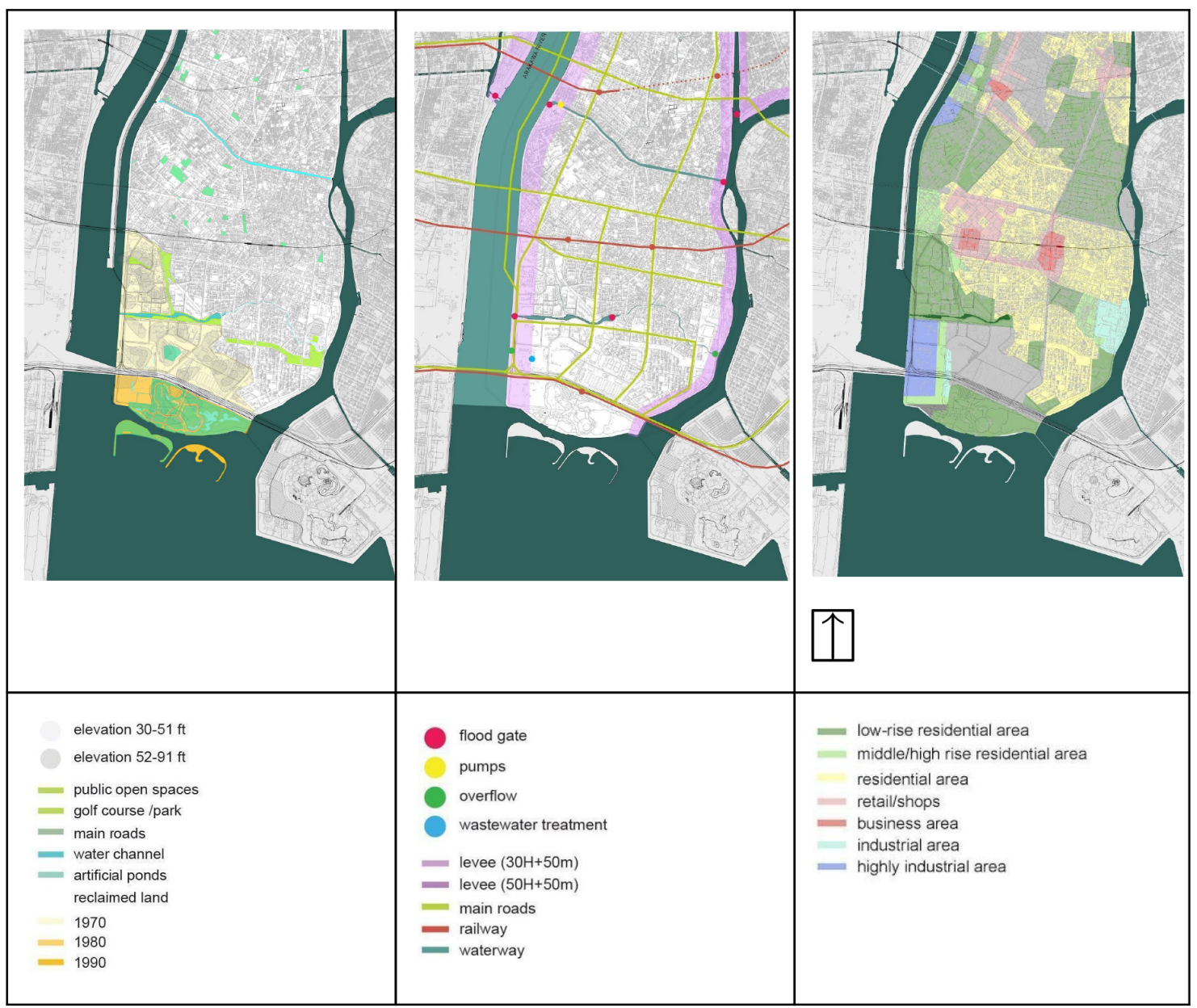

Figure 8. The Dutch layers approach produced a three three-layer mapping of Edogawa ward, Tokyo: (left) surface, (middle) infrastructure, and (right) occupant type (drawn by authors with data and knowledge from [25-27]).

\subsection{Strategy A: Anti Super-Levee}

Strategy A is based on the hypothesis that it is impractical to construct a super levee along the entire shoreline of the district. This is because of high associated costs and displacement of residents, together with the fact that high risk exists only in specific places. The strategy utilized the principle of re-naturalization of a dense urban area by the introduction of a large natural water buffer at the 'meso' (ward) scale by controlling the flow of water at the macro (city) scale. It does this by proposing a multi-functional water basin in Edogawa-ku supported by upstream measures to reduce water flow to the Edogawa river in the event of heavy rainfall. The strategy is based on increasing the conveyance and storage capacities of the channel and floodplain, respectively. This option addresses the urban problem of shrinking public green space in Tokyo while connecting the water with public lives to improve the urban quality (see Figures 9-12). The design process can be characterized as follows:

- Hydraulic interventions upstream (stream capacity and floodplain storage) and at the river mouth (storm surge barrier).

- Studying the weak spots in the urban landscape based on flood risk (inundation from pluvial and fluvial flooding).

- Creation of water storage in the riskiest urban area to improve infiltration capacity. 
- Proposing a water retention system within this identified area by enhancing existing blue-green networks and additional retention zones such as water storage parks, which bring surface water into people's lives.

- Regeneration of built stock and relocation of people from land that will be restored to water or floodplain is critical.

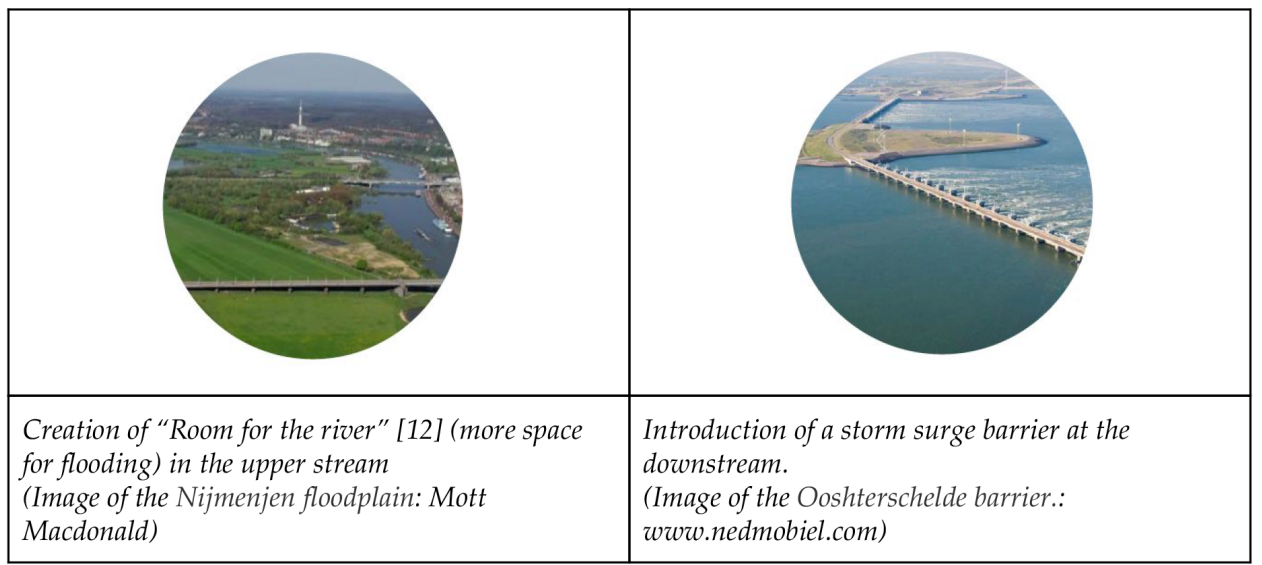

Figure 9. Design features of strategy A (anti super-levee).

\subsubsection{Evaluation of Hydraulic Engineering Measures}

A high-level conceptual assessment was conducted to evaluate the considered engineering measure. A floodgate-controlled confluence of the Arakawa and Nakagawa rivers is located approximately $3 \mathrm{~km}$ upstream from river mouth (see Figure 4). Thus, these rivers are expected to share the water volume during a flood or storm surge [6]. The spatial intervention suggested in this section proposes an open area on the east bank of the river which can be flooded during unfavorable situations (See Figure 12). In other words, the area, referred to as floodplain, will only be inundated if the flow rate exceeds a certain threshold. This floodplain is 450-m wide as shown on the simple geometrical cross-section of Figure 10.

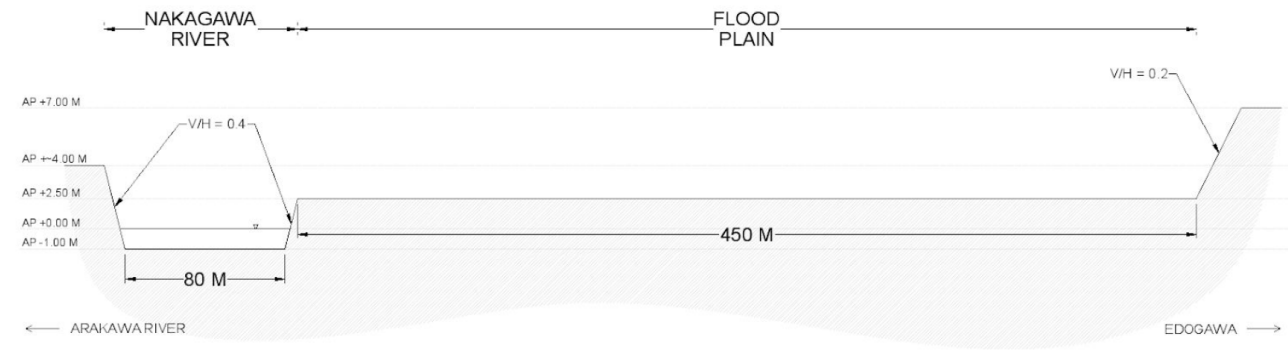

Figure 10. Simplified cross-section of Nakagawa River (source: Google Earth and Arakawa Karyu River Office [14]).

When the volume of water increases along this reach, the floodplain is responsible for providing enough conveyance capacity to prevent the river stage from rising above the levees. Making the zeroth-order approximation of steady flow, the water level or depth can be estimated with Manning's equation. A suitable Manning's coefficient for channel would be 0.022, while the bed slope was determined to be $3 \%$ [28].

The high-level assessment treats the flow rate as a control variable. Figure 8 summarizes the outcome of the assessment. It juxtaposes flow depth of a channel-only cross-section against a river with an added floodplain to delineate the effect of the floodplain. 


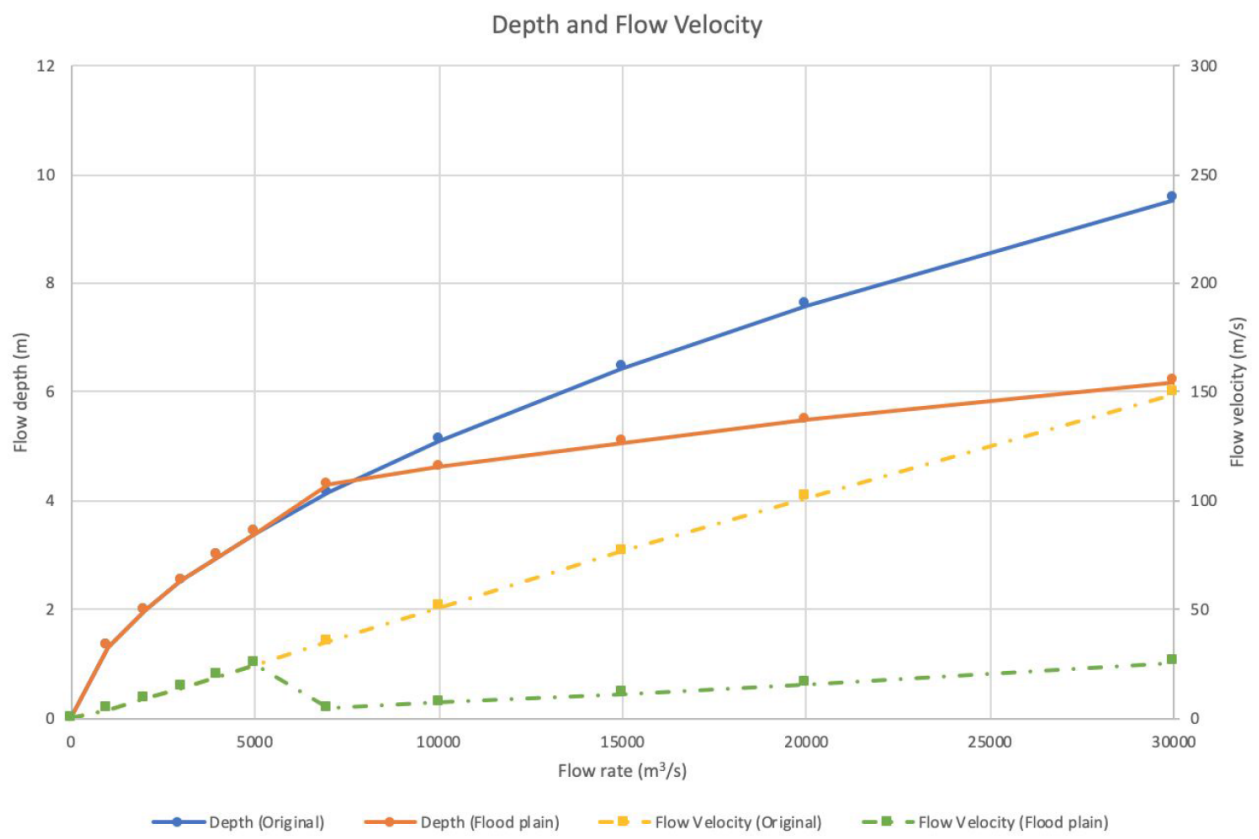

Figure 11. Flow depth and velocity as a function of flow rate $\left(0-30,000 \mathrm{~m}^{3} / \mathrm{s}\right)$.

The existence of the floodplain is evident by the divergence of water depth (shown in blue and orange) at an approximate flow rate of $5200 \mathrm{~m}^{3} / \mathrm{s}$. As flow rate increases, the separation of the two curves increases, displaying the significance of the floodplain. The floodplain helps to reduce the flow depth by $10 \%$ at $10,000 \mathrm{~m}^{3} / \mathrm{s}$ flow rate and $21 \%$ at $15,000 \mathrm{~m}^{3} / \mathrm{s}$. Even though this primitive analysis assumes steady, uniform flow, it demonstrates the influence of the floodplain as additional river capacity. However, a closer look at the significance of the floodplain is required for design by considering unsteady, non-uniform hydraulics.

\subsubsection{Analysis and Observations}

A qualitative spatial analysis is done by overlaying strategy A with the subsurface infrastructure network map (waterway, railway, roads, sewage and electricity lines) (see Figure 12). The sewage system is aligned with the existing waterway and traffic conduits. The proposed water basin respects the layout of the sewage system, but the other waterways are not in alignment with the traffic structure. There is potential to create more waterways by renovating the main sewage line. The shape of the water park is mainly based on the direction of water flow during a fluvial flooding scenario. It is not perfectly aligned with the traffic structure or the sewage system. Most of the electricity networks are above the ground, and some are planned to be buried underground. In principle, they do not affect the strategy. 


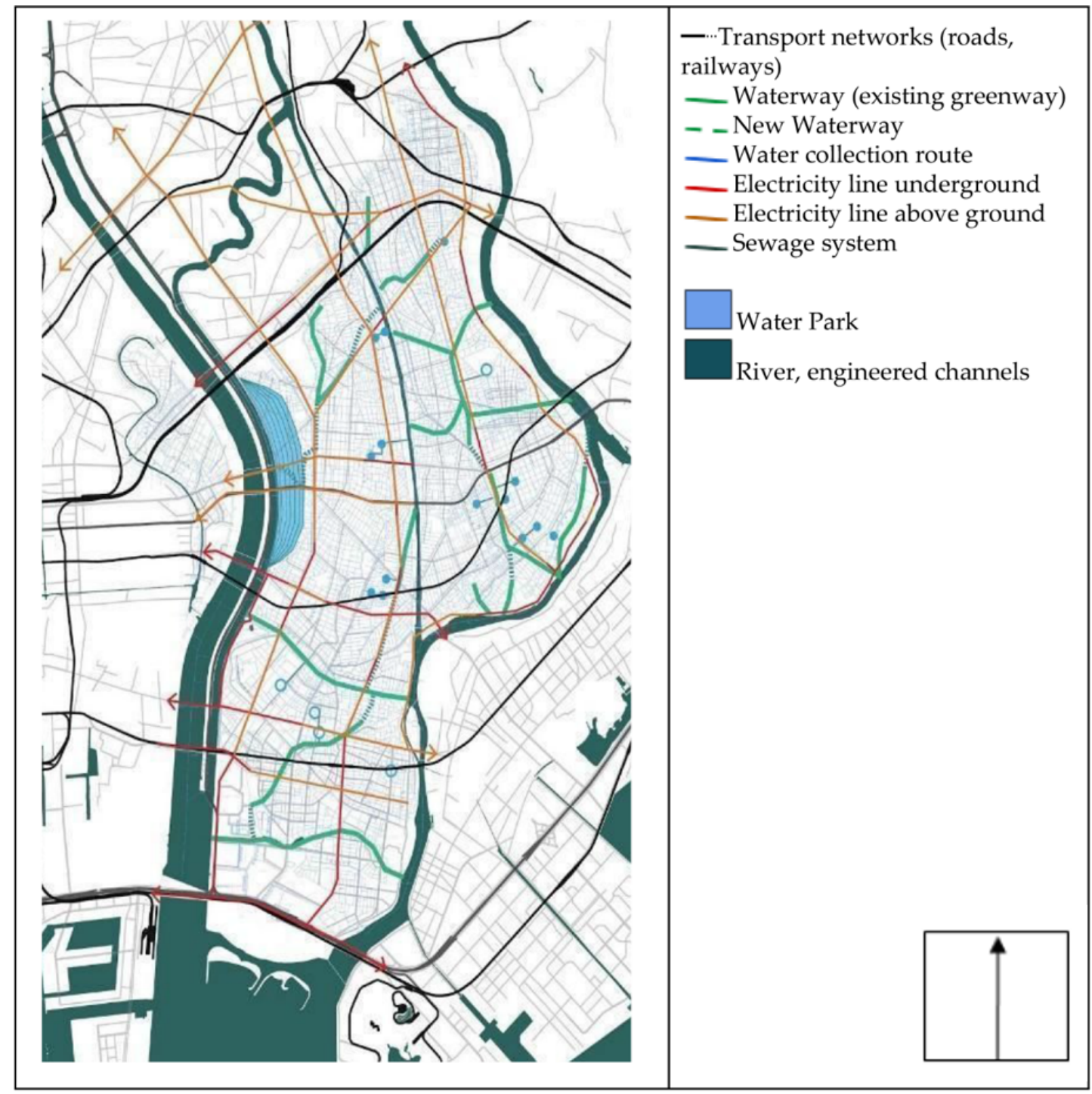

Figure 12. Strategy A-anti super levee overlaid with vital infrastructure (electricity, transport, sewage) (source: drawn using data from MLIT Japan and the Edogawa ward data, 2016) [11,19].

\subsubsection{Overall Recommendations}

Based on the observed interaction between existing subsurface networks and the proposed planning intervention, the following recommendations are made to improve the efficiency of the strategy:

- Engineering calculations must be involved in the initial planning and design stage to assess the feasibility of the strategy.

- More measures to store water are needed, as the capacity of the designed system is insufficient.

- (Soil) In the basin, the filtration and storage capacity of the soil should be maintained to contribute to the function of storing water. Outside of the basin, the soil must be stabilized at selected sites for development.

- (Sewage) The other designed waterway should be aligned with the traffic infrastructure for easier construction and better alignment with the subsurface system. More waterways can be created along the main sewage lines and roads.

- (Power) Laying the underground electricity line provides an opportunity to enlarge streets or green areas along streets. These should be considered as potential areas for more water storage. 


\subsection{Strategy B: Pro Super-Levee}

Strategy B is based on the hypothesis that the super levee is a robust flood defense concept and must be explored to understand how it can be further integrated into the design of the urban environment. The super levee is perceived as an additional land mass that exhibits more resistance to inner slope failure due to erosive flow. When water exceeds the height of the embankment, the flow rate over the inner slope of a super embankment will be less severe than over a normal levee, because the inner slope of the super levee is much less steep than that of a normal levee. However, the problem lies in the 'one size fits all approach' currently being adopted. The group worked towards a planning strategy at the meso (ward) scale that customizes the super levee to suit the requirements of Edogawa ward. First, geomorphology of the site is examined to determine highly vulnerable locales. Based on the analysis, selective thickening/strengthening of the super levee will be executed in combination with a regular levee network. The strategy suggests a better hydraulic and urban design alternative to adapt to the super levee (see Figure 13). The design process can be characterized as follows:

1. Studying the weak spots in the landscape based on flood risk (inundation from pluvial and fluvial measures) along with liquefaction zones for earthquakes.

2. Integrate with current evacuation routes for emergencies (see Figure 14).

3. Propose new urban design typologies to adapt to the interface between the super levee and the surroundings.

4. Making room for water storage in case of large calamities by allocating 'sacrificial' land parcels for forced flooding.

5. Reprogramming the urban plan of the super levee to transform it into a productive landscape. Urban agriculture is proposed as an economic alternative for land acquired from original landowners. This is to retain environmental quality for massive built infrastructure and for owners to maintain 'title' to the land.

\begin{tabular}{|l|l|l|}
\hline $\begin{array}{l}\text { Creation of "floodable" land } \\
\text { parcels } \\
\text { (Image ref:: BIG Architects) }\end{array}$ & $\begin{array}{l}\text { Combine the emergency evacuation } \\
\text { pattern with Tokyo's proposed } \\
\text { Green Belt network (Watanabe: The } \\
\text { abandonment of Tokyo's Green Belt } \\
\text { and the search for a new discourse } \\
\text { of preservation in Tokyo's suburbs) } \\
\text { to find a green backbone to improve } \\
\text { water infiltration } \\
\text { (Image ref.: Dogma Architects) }\end{array}$ & $\begin{array}{l}\text { Creation of food production belt } \\
\text { on the super levee area. }\end{array}$ \\
\hline
\end{tabular}

Figure 13. Design features of Strategy B (pro super levee). 


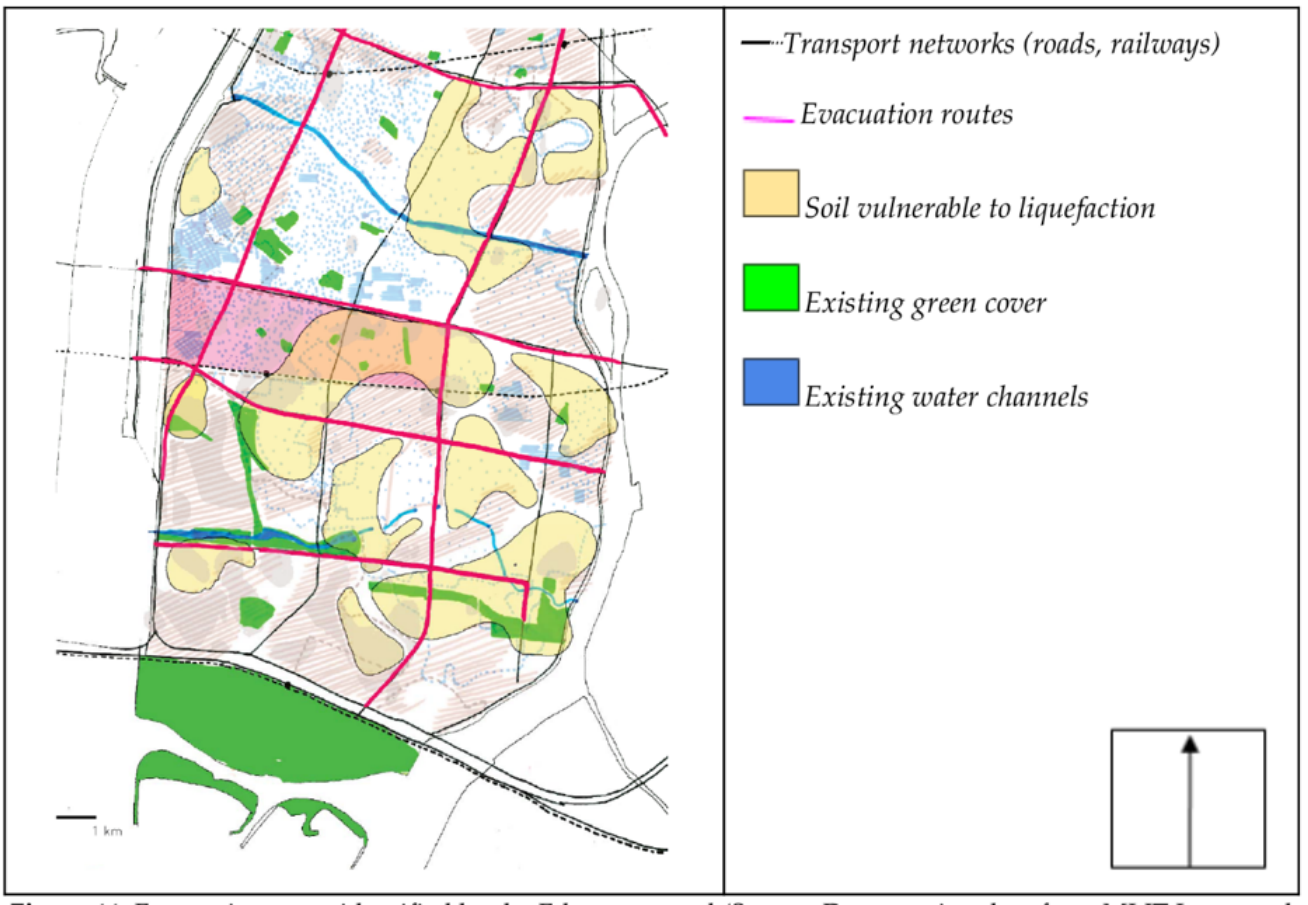

Figure 14. Transport routes, drainage channels, and vulnerable areas in Edogawa ward (drawn by authors using data from $[19,20])$.

\subsubsection{Evaluation of Hydraulic Engineering Measures}

Compared to the conventional embankment or dike, the super embankment (super levee) concept differs in width but not in height. The super embankment manifests a much flatter inner slope and reaches widths of 300 to $500 \mathrm{~m}$, in contrast to the 20 to $30 \mathrm{~m}$ width of conventional embankments. To compensate the substantial area it requires, the inner slope of the super embankment is envisaged as land for new urban development area as it provides higher ground elevation and consequently less inundation risk (see Figure 15) [8,9].
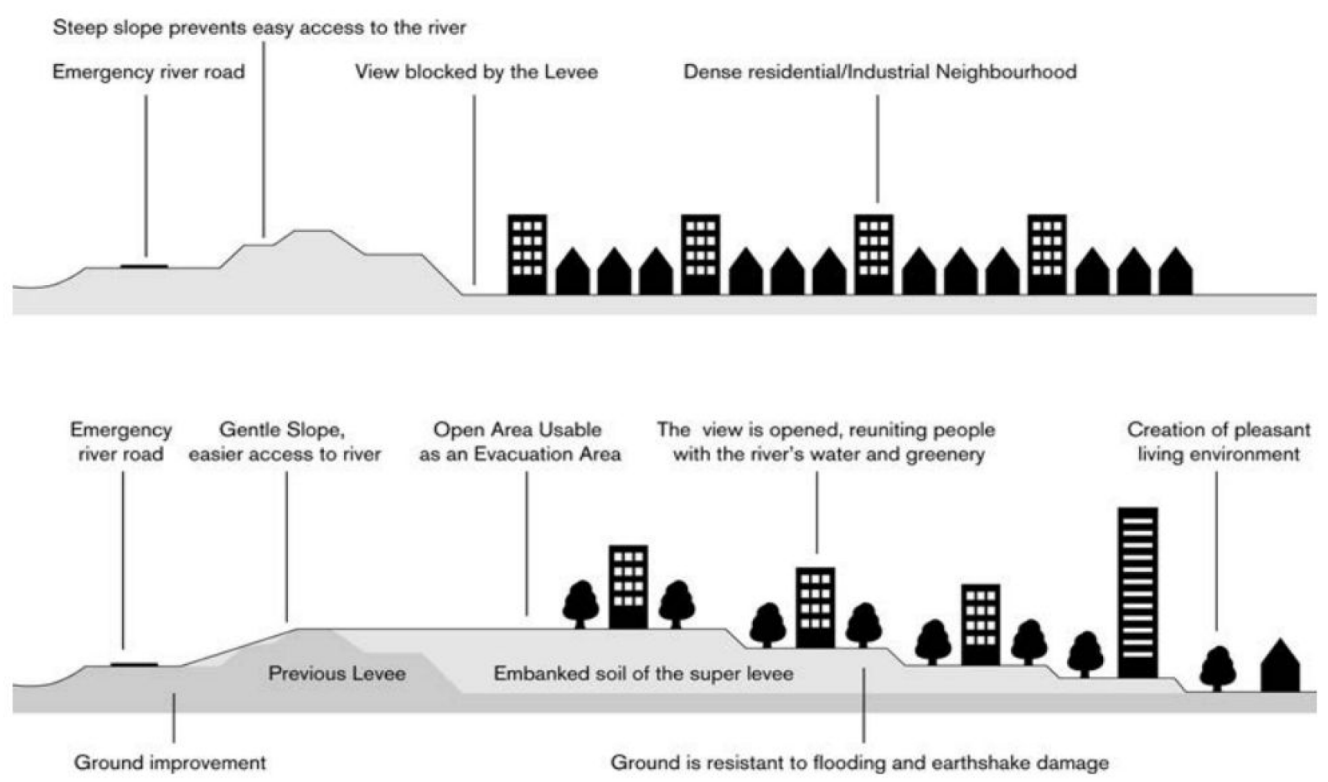

Figure 15. Comparison of a traditional (top) and super embankment (bottom), also known as a "super levee" (Arakawa-Karyu River Office and MLIT) $[8,19]$. 
Other than its purpose as an elevated surface, the concept also offers engineering virtues. One of the advantages it brings is the increase of shear capacity. To be able to withstand horizontal pressure from the water, an embankment must retain an adequate shear capacity, which largely depends on friction and thus mass of the levee. In this case, the super embankment can be perceived as an additional land mass standing behind a traditional dike. Therefore, the supplemental structural weight of the embankment increases the friction force and shear capacity. Moreover, the width of the super embankment is advantageous to minimize piping failure. Piping failure of a dike is caused by the development of a porous flow channel beneath the structure. Chow, Thusyanthan and Jonkman et al. [29-31] studied the flow front of them. of water in porous media with experiments and reported porous flow velocity $\mathrm{V}[\mathrm{m} / \mathrm{s}]$ dependence on hydraulic conductivity $\mathrm{K}[\mathrm{m} / \mathrm{s}]$ and pressure gradient i [m/m] [29-31], as shown in Darcy's Law Equation (1).

$$
\mathrm{V}=\mathrm{Ki}=\mathrm{K} \Delta \mathrm{h} / \Delta \mathrm{l}
$$

Equation (1) represents the ratio of the difference in hydraulic head $\mathrm{h}[\mathrm{m}]$ to the seepage length $1[\mathrm{~m}]$. Since the main function of the embankment is to separate land from water, the establishment of a hydraulic gradient is inevitable. While water tries to penetrate through the porous medium, flow experiences energy loss due to interaction with the soil. The broader super embankment base is a favorable measure to prevent piping failure as it can dissipate more energy due to greater seepage length. For the standard levee, one way to minimize piping risk is to install an impermeable layer, usually sheet pile or cut-off wall, under the embankment. Such structures force water to cover more distance before it finally surfaces. If water must travel a long distance from one side of the structure to another due to subsurface interference, the probability of seepage failure is reduced.

In comparison to a regular embankment, the super levee also exhibits more resistance to inner slope failure due to erosive flow. When water exceeds the height of the embankment, the flow rate on the inner side of a super embankment will be less severe because of the mild inner slope. Therefore, greater over topping is required to reach the critical flow that can erode soil or protection layers on the inner slope. Apart from these positive traits, the construction of a super embankment demands sound financial support not only for the construction work but also for the relocation of existing structures. The duration of construction is also expected to be lengthy $[9,19]$.

\subsubsection{Analysis and Observations}

By overlaying the proposed designs with maps of vital infrastructure, observation of how they agree or conflict with each other can be made (see Figure 16):

1. The adapted super levee structure and evacuation routes are designed based on the existing urban fabric and infrastructure.

2. The evacuation routes are aligned with the drainage system, but since they are elevated, it may impact the layout (or depth) at which the sewage network is set.

3. The main electricity lines (above or under the ground) are aligned with the designed infrastructure.

\subsubsection{Overall Recommendations}

Based on the observed interaction between existing subsurface networks and the proposed planning intervention, the following recommendations are made to improve the efficiency of the strategy (see Figure 16):

1. The super levee can be adapted, but a certain minimum levee width must be maintained to make sure the system works.

2. (Soil) Soil should be stabilized along the levee in case of shaking scenarios. Different water levels during flood events in different parts of the ward should be treated uniquely. For example, the lower ground level, where development will be retained as it is. makes it vulnerable to flooding. Thus, the infiltration and storage capacity of the soil should be increased in these areas. 
3. (Sewage) The existing sewage system within the proposed super levee area needs to be raised to meet an effective height for the maintenance and for the strength of dike. Due to the introduction of higher evacuation routes, lower lying areas will become more prone to flooding. The sewage system- and water storage capacity needs to be increased within this area which can be done by introducing a water canal and other urban block level interventions.

4. (Power) To keep the energy distribution uninterrupted during times of flooding, the elevated areas can accommodate elevated energy infrastructure, with energy storage units included. This also ensures supply of electricity along the evacuation route.

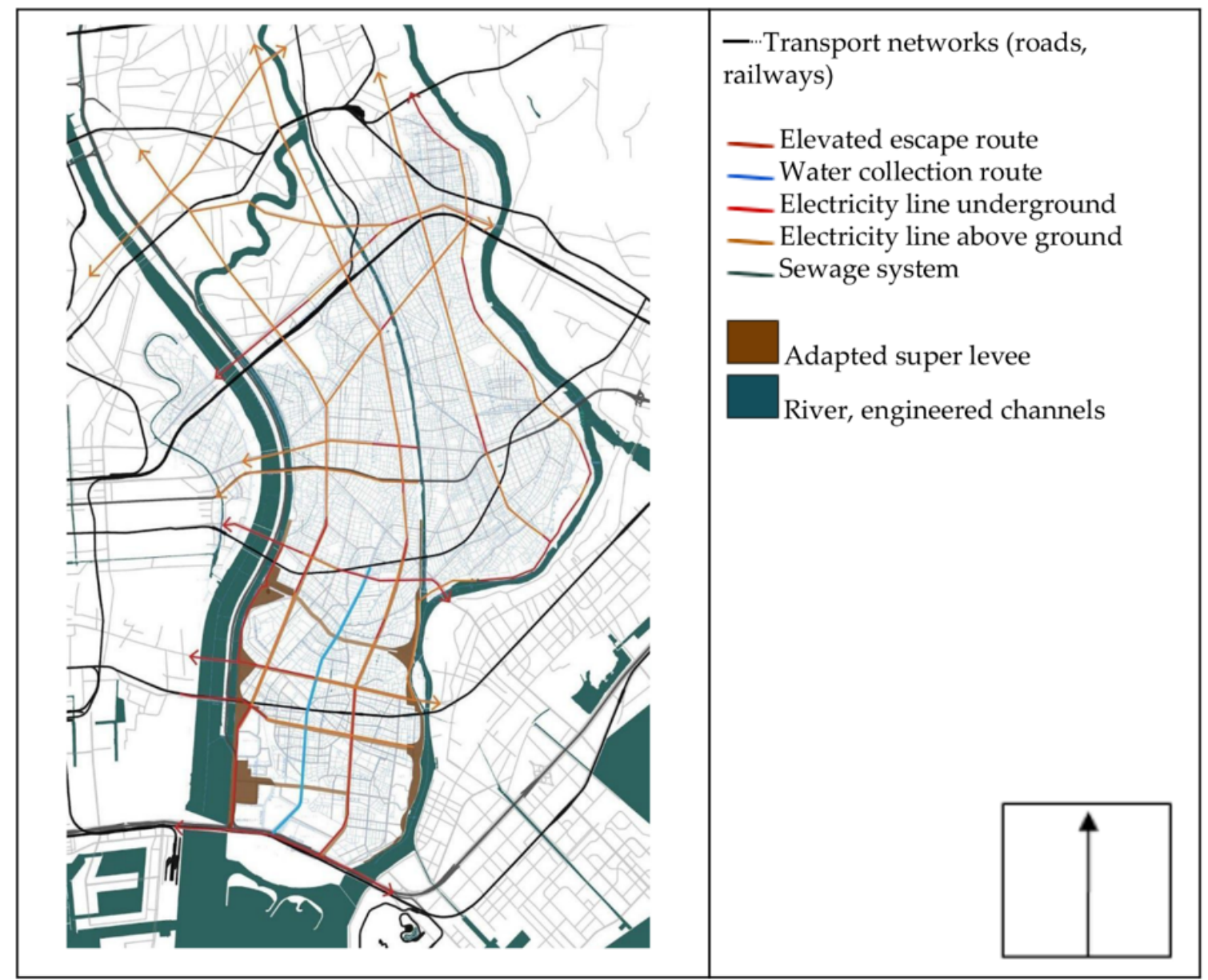

Figure 16. Strategy B-pro/integrated super levee overlaid with vital infrastructure (electricity, transport, sewage) (Source: Drawn using data from MLIT Japan and Edogawa Ward data, 2016) [11,19].

\section{Discussion}

This paper proposes how interdisciplinary design can juxtapose, apply, combine, synthesize, integrate or transcend parts of five disciplines [11] within the 'Dutch approach' [14] and gives specific insights in 'implementation' barriers that exists between the fields of hydraulic engineering, urban design and subsurface infrastructure planning. In relation to methodologies in literature to improve urban resilience, this approach is focused on content integration in urban design and not on a general holistic approach that proposes indicators or general guidelines for the analysis phase. Serre et al. [32] emphasizes the their front. The importance of integrated reflection on the resilience concept to arrive at a spatial decision support system using the same set of indicators. These are very useful—but restricted in relation to the approach proposed in this paper.

Beyond the formulation of the inventory (Step 1) and analysis of site (Step 2), the proposition of the two Strategies A and B was done in co-creation (Step 3). The evaluation of the alternatives 
(Step 4) reveals the extent of connect and disconnect between planning and engineering perspectives in decision making for urban flood management. It became clear that, although vital subsurface infrastructure is essential to flood management, engineering and planning disciplines do not have a method for integrating the subsurface infrastructure in decision making (such as the levee system with the soil or sewage networks). In literature there is the DS3 model in which resistance, absorption and recovery capacities of all urban networks (including the subsurface) is analyzed and used to establish indicators of the potential of resilience [32]. The objective is to understand and especially integrate resilience in management and planning policies by creating a spatial decision support tool for neighborhood-level resilience analysis. This method is, however, limited to identifying resilience characteristics and does not integrate flood management in general urban strategy and design.

Besides integration in qualitative terms, integration in quantitative terms should be taken into consideration. Measures used in both strategies are proven measures drawn from existing practices in front-running cases like the Room for the River, allocating land parcels for forced flooding, reinforcing dikes, increasing infiltration area for water, etc. While they function for this site, their suitability should be reconsidered when they are applied to other cases. For example, in strategy A which features a water basin, the calculations are restricted to the meso (ward) scale, as the water park and canals at the scale are able to handle pluvial floods but not fluvial floods, while the restored floodplain addresses only fluvial flooding. In quantitative terms, the proposal would be completed only by consideration of the full river reach, from the upstream watershed to the sea. This proves again that generic solutions to global problems can be utilized as long as they are contextualized and modified.

As concluded by [33], "research-practice partnerships underline the growing need for territories and communities to acquire tools in order to better understand the concept of resilience, and especially to apply it practically to their territories, habits, populations, operating modes, knowledge and perspectives". Crucial for the process and analysis using research by design in step 5 is the consideration of various hierarchies (or scales) in the planning system for achieving a higher level of resilience. In combination with the lower scales, we can not only systematically address the vital surface infrastructure, but also allow for sufficient detail in the urban design quality, which contributes to the feasibility of implementing changes. These changes are part of the resilience strategy and work towards enforcing the system to be able to answer to stress or shock.

\section{Conclusions}

This project is an attempt by designers and engineers to jointly explore visions and methods for the future of urban flood resilience systems. This involved gathering related literature and cases (inventory), choosing suitable methods to approach the problem, proposing strategic design alternatives for a real site and evaluating the designs from a multidisciplinary perspective. This included consideration of hydraulic systems, soil type and subsurface infrastructure networks. The 'research by design' exploration contributed to the potential of an integrated design process in a multidisciplinary way, which answers the research question of this paper. First, methods to approach the multidisciplinary topics and the effectiveness of these methods are explored through the 'Dutch layer approach' and the 'SEES' methodologies. Second, the design and evaluation process highlight the gaps between urban design and engineering perspectives; these gaps reduce the possibility of enhanced resilience in the long-term. The design and evaluation process also helps to recommend improvement measures. These measures not only serve as actual tools that can be used, but also serve to kick start further debate on integrated sustainable growth. The results of the process can be applied to other projects to see how we can improve this combination in practice, and open avenues for further research. By improving the integration of urban quality, engineering, and vital subsurface infrastructure, a more resilient urban system can be formed to combat the intensifying climate risks of the next century.

Supplementary Materials: The study of urban flood risk interventions as part of this project was presented at an exhibition at Gallery Ten Tokyo, March 2017. http:/ / www.gallery-ten.tokyo/archives/category/22-challenge s-in-flooding. 
Author Contributions: Conceptualization, Administration, Funding Acquisition, Resources: F.H., J.B., Y.Y.; Methodology, Formal Analysis and Investigation: S.K., J.L., J.S., M.D.; Hydraulic Analysis: J.S., J.B.; Spatial Planning and Design: S.K., J.L., M.D.; Writing-Original Draft Preparation: F.H., S.K., J.L., J.S., M.D.; Final Writing-Review and Editing: S.K., J.B., F.H., J.L.; Visualizations: S.K., J.L., J.S., M.D.

Funding: This research was funded by TU Delft Deltas, Infrastructures and Mobility Initiative: https: / www.tu delft.nl/infrastructures/, and by a bilateral grant from Netherlands Organization for Scientific Research (NWO) and the Japan Society for the Promotion of Science (JSPS).

Acknowledgments: The authors would like to thank Bas Jonkman, Hiroshi Takagi, and Miguel Esteban for their support during ground research and review process. We also thank Akihiko Ono-san, Daiki Mabuchi, Ayano Yamaguchi, Manami Hasegawa, Richard Crichton, Non Okumura, Bas Hoersten and Shaswati Chowdhury for their support during the workshop, resource selection, fieldwork and general hospitality in Japan. Nobuyuki Tsuchiya of the Japan Riverfront Research Center and the Edogawa ward office was also instrumental in our information gathering.

Conflicts of Interest: The authors declare no conflict of interest. The funders had no role in the design of the study; in the collection, analyses, or interpretation of data; in the writing of the manuscript, or in the decision to publish the results.

\section{References}

1. Lim, B.; Spanger-Siegfried, E.; Burton, I.; Malone, E.; Huq, S. Assessing current climate risks. In Adaptation Policy Frameworks for Climate Change: Developing Strategies, Policies, and Measures; United Nations Development Programme (UNDP): New York, NY, USA, 2004.

2. Meerow, S.; Newell, J.P.; Stults, M. Defining urban resilience: A review. Landsc. Urban Plan. 2016, 147, 38-49. [CrossRef]

3. Cutter, S.L.; Barnes, L.; Berry, M.; Burton, C.; Evans, E.; Tate, E.; Webb, J. A place-based model for understanding community resilience to natural disasters. Glob. Environ. Chang. 2018, 18, 598-606. [CrossRef]

4. Klijn, F.; de Bruin, D.; de Hoog, M.C.; Jansen, S.; Sijmons, D.F. Design quality of room-for-the-river measures in the Netherlands: Role and assessment of the quality team (Q-team). Int. J. River Basin Manag. 2013, 11, 287-299. [CrossRef]

5. Hooimeijer, F.L.; Bricker, J.D.; Iuchi, K. An Interdisciplinary Approach to Urban Reconstruction after the 2011 Tsunami; TU Delft DeltaLinks: Delft, The Netherlands, 2018.

6. De Graaf, R.; Hooimeijer, F. (Eds.) Urban Water in Japan; CRC Press: Boca Raton, FL, USA, 2008; Volume 11.

7. Stalenberg, B.; Vrijling, H.; Kikumori, Y. Japanese lessons for Dutch urban flood management. In Proceedings of the Water Down Under, Adelaide, Australia, 14-17 April 2008; p. 66.

8. Arakawa-Karyu River Office. Ministry of Land, Infrastructure and Transport, Japan. In Super Levees Guidebook; Arakawa-Karyu River Office: Tokyo, Japan, 2007.

9. Cameron, M. Tokyo Building Enormous "Super-Levees" to Hold Back Its River. 2013. Available online: https:/ / nextcity.org/daily/entry/tokyo-is-building-enormous-super-levees-to-hold-back-its-river (accessed on 25 July 2019).

10. Stember, M. Advancing the Social Sciences Through the Interdisciplinary Enterprise. Soc. Sci. J. 1991, 28, 1-14. [CrossRef]

11. Huutoniemi, K.; Klein, J.T.; Bruun, H.; Hukkinen, J. Analyzing interdisciplinarity: Typology and indicators. Res. Policy 2010, 39, 79-88. [CrossRef]

12. Miller, R. Varieties of interdisciplinary approaches in the social sciences. In Issues in Integrative Studies; An Occasional Publication of the Association for Integrative Studies: Rochester, MI, USA; 1982; pp. 1-37.

13. Heinzlef, C.; Ganz, F.; Serre, D.; Becue, V. Coping with Urban Floods: A Special Decision-Support System to Improve Resilience. In Proceedings of The 21st Conference on Geo-Information Science, Lund, Sweden, 12-15 June 2018

14. Ministry of Infrastructure and Water Management; Ministry of Education, Culture and Science ; Ministry of the Interior and Kingdom Relations; Ministry of Economic Affairs and Climate. Action Agenda for Spatial Design 2017-2020 Working Together on the Strength of Design; Ministry of Infrastructure and Water Management: The Hague, The Netherlands; Ministry of Education, Culture and Science: The Hague, The Netherlands; Ministry of the Interior and Kingdom Relations: The Hague, The Netherlands; Ministry of Economic Affairs and Climate: The Hague, The Netherlands, 2016. 
15. Stappers, P.J. Doing design as a part of doing research. In Design Research Now; Springer: Berlin, Germany, 2007; pp. 81-91.

16. Research by Design Is Any Kind of Inquiry in Which Design Is a Substantial Part of the Research Process. Available online: http:/ / reseaerch.wikidot.com/research-by-design (accessed on 25 July 2019).

17. Thompson, J.D.; Tuden, A. Strategies, structures and processes of organizational decision. In Readings in Managerial Psychology; Leavitt, H.J., Pondy, R., Eds.; University of Chicago Press: Chicago, IL, USA, 1964.

18. Rittel, H.W.J.; Webber, M.M. Dilemmas in a General Theory of Planning. Policy Sci. 1973, 4, 155-169. [CrossRef]

19. Integrated Disaster Information System (DiMAPS). Ministry of Land, Infrastructure, Transport and Tourism (MLIT). 2017. Available online: http:/ / www.mlit.go.jp/saigai/dimaps/index.html (accessed on 23 April 2017).

20. Official Website of Edogawa Ward. Available online: http:/ / www.city.edogawa.tokyo.jp/foreign/ (accessed on 11 December 2016).

21. Official Website for Tokyo Green Belt. Available online: http://www.mlit.go.jp/hakusyo/kensetu/h12_2/h 12/html/C1Z01000.html (accessed on 23 November 2018).

22. Website Describing the Tsurumi River Multipurpose Retarding Basin. Available online: http://www.japanr iver.or.jp/EnglishDocument/DB/file/004\%20Kanto\%2023/02.htm (accessed on 23 November 2018).

23. Official Website of the Arakawa-Karyu River Office. Available online: https://www.pref.saitama.lg.jp/a05 05/901-20091202-17.html (accessed on 17 January 2017).

24. Challenges in Coastal Flood Risk Reduction. Collaborative Workshop between the Netherlands and Japan. 2016. Available online: https:/ / pure.tudelft.nl/portal/files/20671410/NWO_JSPS_Joint_Seminar_2016_ Report.pdf (accessed on 25 July 2019 ).

25. van Schaick, J.; Klaasen, I. The Dutch layers approach to spatial planning and design: A fruitful planning tool or a temporary phenomenon? Eur. Plan. Stud. 2011, 19, 1775-1796. [CrossRef]

26. Hooimeijer, F.; Kuzniecow, T.; Lafleur, F. Intelligent Use of Subsurface Infrastructure for Surface Quality; TU Delft: Delft, The Netherlands, 2016.

27. Hooimeijer, F.L.; Maring, L. The significance of the subsurface in urban renewal. J. Urban. Int. Res. Placemaking Urban Sustain. 2018, 11, 303-328. [CrossRef]

28. Chow, V.T. Open-Channel Hydraulic; McGraw-Hill: New York, NY, USA, 1959.

29. Kundzewicz, Z.W.; Takeuchi, K. Flood protection and management: Quo vadimus? Hydrol. Sci. J. 1999, 44, 417-432. [CrossRef]

30. Thusyanthan, N.I.; Madabhushi, S.P.G. Experimental study of vibrations in underground structures. Proc. Inst. Civil. Eng.-Geotech. Eng. 2003, 156, 75-81. [CrossRef]

31. Jonkman, S.N.; Schweckendiek, T. Developments in levee reliability and flood risk analysis in the Netherlands. In Geotechnical Risk and Safety V, Proceedings of the 5th International Symposium on Geotechnical Safety and Risk, Rotterdam, The Netherlands, 13-16 October 2015; IOS Press: Amsterdam, The Netherlands, 2015.

32. Serre, D.; Heinzlef, C. Assessing and mapping urban resilience to floods with respect to cascading effects through critical infrastructure networks. Int. J. Disaster Risk Reduct. 2018, 30, 235-243. [CrossRef]

33. Heinzlef, C.; Becue, V.; Serre, D. Operationalizing urban resilience to floods in embanked territories-Application in Avignon, Provence Alpes Côte d'azur region. Saf. Sci. 2019, 118, 181-193. [CrossRef]

(C) 2019 by the authors. Licensee MDPI, Basel, Switzerland. This article is an open access article distributed under the terms and conditions of the Creative Commons Attribution (CC BY) license (http://creativecommons.org/licenses/by/4.0/). 